\title{
Classification of Borax Content in Tomato Sauce Through Images Using GLCM
}

\author{
Reyhan Achmad Rizal \\ University Prima Indonesia \\ Medan, Indonesia \\ reyhanachmadrizal@unprimdn.ac.id
}

\author{
Mario Susanto \\ University Prima Indonesia \\ Medan, Indonesia \\ magmariosusanto@yahoo.com
}

\author{
Andy Chandra \\ University Prima Indonesia \\ Medan, Indonesia \\ andychandra135@gmail.com
}

Submitted: Feb 28, 2020

Accepted: Mar 15, 2020

Published: Apr 1, 2020

\begin{abstract}
One of the food products that need to be reviewed for safety and is the most consumed is tomato sauce, although it contains a large amount of water in the sauce which has a long shelf life because it contains acid, sugar, salt, and is often given preservatives. The purpose of this study was to determine the tomato sauce using harmful preservatives such as the addition of borax. The dataset used in this study is the image of tomato sauce containing borax and not with the number of samples 400 images of tomato sauce with different comparison percentages starting from the image of tomato sauce with $70 \%$ borax content, image of tomato sauce with $50 \%$ borax content, image tomatoes with $30 \%$ borax content and image of tomato sauce that does not contain borax. A sampling of images using a camera phone brand xiaomi note 5 by mixing borax in the original sauce before the sample is used for the training and testing process. The classification results show the gray level co-occurrence matrix (GLCM) method is quite optimal in classifying tomato sauce data containing borax and not with an average percentage of the introduction of $88 \%$.
\end{abstract}

Keywords - Tomato Sauce, Borax, GLCM

\section{INTRODUCTION}

The sauce is a type of flavoring that is usually added to food, the sauce can be interpreted as a thick liquid made from pasta or fruit pulp that is able to give a distinctive aroma and taste to food. Sauces can be made from fruits and vegetables such as tomatoes and chilies (Usman, Herawati, \& Fitriani, 2019). Tomato sauce is made from a mixture of tomatoes and spices and then paste used is pink in accordance with the color of tomatoes used, although it contains large amounts of water the sauce has a long shelf life because it contains acids, sugar, salt, and often given preservatives (Ray, Saha, Raychaudhuri, \& Chakraborty, 2016). According to (Nkhata \& Ayua, 2018) a good temperature to increase the shelf life of tomato sauce is at $6^{\circ} \mathrm{C}$. One of the food products that need to be reviewed for safety and is the most consumed is tomato sauce, tomato sauce is usually consumed as a compliment when people consume chicken noodles, meatballs, tempura, pentol, fried rice, and others.

Many food industries are developing but not all are honest in their processing, such as the addition of harmful preservatives or the provision of preservatives that are not in accordance with the recommended quantities such as adding borax to the sauce to increase the shelf life of the sauce, this can cause health problems for those who consume it. Borax is a white crystalline powder containing boron, borax is generally used for anti-fungi, wood 
preservatives, and antiseptic ingredients. Consumption of foods containing borax can cause poisoning and can even cause death (Lathifah, Turista, Azizah, \& Khulaifi, 2019). Making sauces that are safe and healthy without the addition of preservatives can be used as food products that are good for health or can also be done to adjust the $\mathrm{pH}$ and temperature power in the production process. Setting the $\mathrm{pH}$ and temperature in the process of making sauces can improve the nutritional value, taste and long-term shelf life (Nursari, Karimuna, \& Tamrin, 2016).

Based on these problems, research is needed to determine which tomato sauce is feasible and not suitable for consumption. In this study a tomato sauce classification system will be made through an image using the gray level co-occurrence matrix (GLCM) with sample data generated by researchers through a cellphone camera, where Gray Level Co-Occurrence Matrix (GLCM) method has quite good stages in the process of object recognition, as for the stages, namely: the initial stages of forming a matrix of twopixel pairs that line in the direction of $0^{\circ}, 45^{\circ}, 90^{\circ}$ or $135^{\circ}$, the second step forms a symmetric matrix by adding the initial matrix with the transpose value, the third stage normalizes the matrix by dividing each matrix element by the number of pixel pairs then the resulting value will be used to produce 4 features of the gray level co-occurrence matrix (GLCM) ) namely energy, contrast, correlation, and entropy (Rizal, Gulo, Sihombing, Napitupulu, Gultom, \& Siagian, 2019)

\section{Literature REVIEW}

GLCM feature extraction is widely proposed by researchers because it can be applied in various problems such as Recognition of facial expressions proposed by (Rizal, Gulo, Sihombing, Napitupulu, Gultom, \& Siagian, 2019) GLCM recognition rates reach an average of $80 \%$, (Sukiman, Suwilo, \& Zarlis, 2019) proposed feature extraction using GLCM and LVQ in facial recognition with a $90 \%$ recognition rate and (Öztürka \& Akdemir, 2018) applied the Feature Extraction and Classification method for Histopathological Images using GLCM, LBP, LBGLCM, GLRLM, and SFTA .

\subsection{Tomato Sauce}

Tomato sauce is made from a mixture of tomatoes and spices and then paste used is pink according to the color of the tomato used, although it contains large amounts of water the sauce has a long shelf life because it contains acids, sugar, salt, and often given preservatives (Ray, Saha, Raychaudhuri, \& Chakraborty, 2016)

\subsection{Borax}

Borax is a white crystalline powder containing boron, borax is generally used for anti-fungi, wood preservatives, and antiseptic ingredients. Consumption of foods containing borax can cause poisoning and can even cause death (Lathifah, Turista, Azizah, \& Khulaifi, 2019)

\subsection{GLCM (Gray Level Co-Occurrence Matrix)} GLCM is a method that is often used in object recognition because the method of glcm has quite good steps in the process of object recognition, as for the stages, namely: the initial stages of forming a matrix of two-pixel pairs that align in the direction of $0^{\circ}, 45^{\circ}, 90^{\circ}$ or $135^{\circ}$, the second step forms a symmetrical matrix by adding the initial matrix with the transpose value, the third step normalizes the matrix by dividing each matrix element by the number of pixel pairs and then the resulting value will be used to produce 4 features of the gray level cooccurrence matrix (GLCM), namely energy, contrast, correlation, and entropy (Rizal, Gulo, Sihombing, Napitupulu, Gultom, \& Siagian, 2019).

\section{Proposed METHOd}

\subsection{Datasheet}

Datasheet used in this study is the original tomato sauce image data and the image of tomato sauce that has been mixed with borax with different percentages starting from the image of the sauces with $70 \%$ borax content, the image of sauces with $50 \%$ borax content, the image of tomato sauce with borax content $30 \%$ and the image of tomato sauce that does not contain borax. A sampling of images using a camera phone brand Xiaomi Note 5 by mixing borax in the original sauce before the sample is used for the training and testing process.

3.2. Research Steps General research steps developed in this study can be seen in Figure 1.

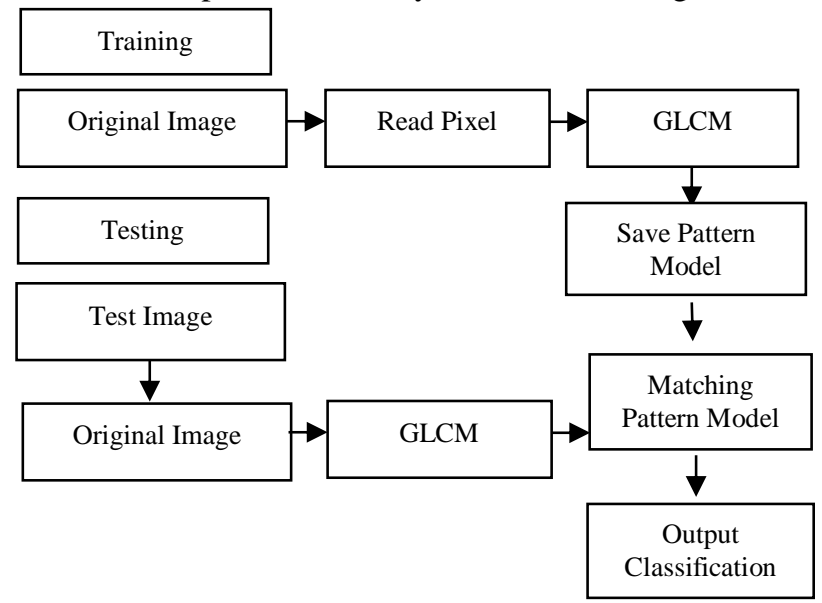

Figure 1. General Research Steps for Tomato Sauce Recognition 
In figure 1. there are two processes, namely the training process and the testing process, the input image training process is carried out pre-processing with grayscale and continued by extracting features from the tomato sauce image using GLCM and the extracted pattern model will be saved while in the testing phase, input image is preprocessing with grayscale and extracted using GLCM then proceeding to fit the pattern model matching, if the pattern is similar or close to the training pattern, the output of the classification is the result of the classification of tomato sauce image containing borax and not. The overall research steps to the introduction of saous tomato images containing borax and those not constructed in this study are illustrated in figure 2 .

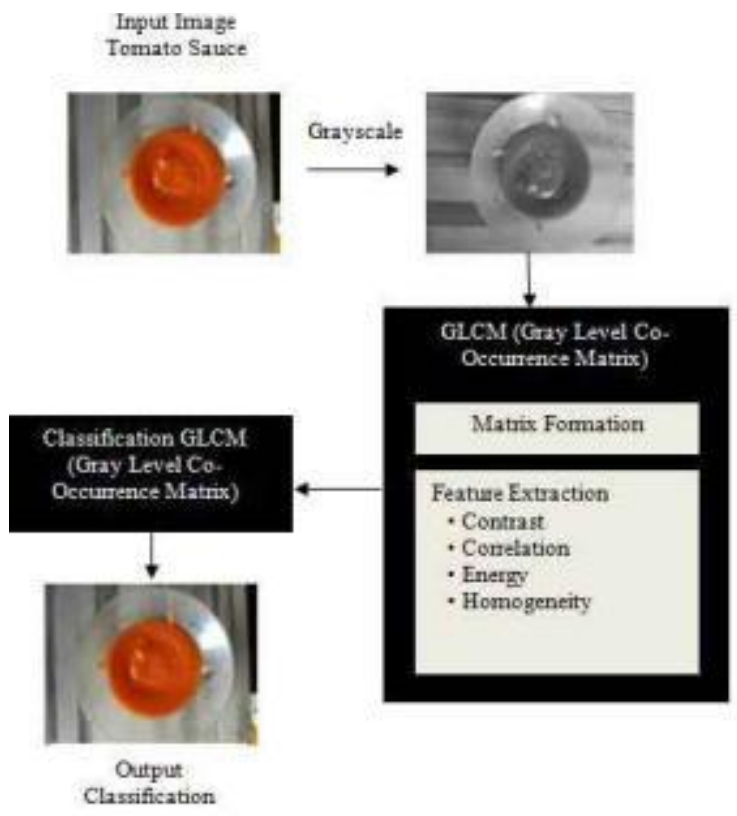

Figure 2. Overall Research Steps Introduction to Tomato Sauce Image

In Figure 2. can be seen after the system receives the input of the original tomato sauce image, the system will process the input image into grayscale, then the grayscale image is processed again using the steps in the GLCM method to generate weight values from the tomato sauce image and stored as a reference pattern for image classification. tomato sauce. The weight of the testing feature extraction will be matched to the weight of the training feature extraction using GLCM for recognition and is classified into the image of the tomato sauce containing borax or not.

\section{RESUlT AND DISCUSSION}

\subsection{Tomato Sauce Image Samples}

Samples of tomato sauce images containing borax and not used in this study amounted to 400 tomato sauce images with different percentages starting from the image of sauces with $70 \%$ borax content, image sauces with $50 \%$ borax content, image of tomato sauce with $30 \%$ borax content and image of tomato sauce that does not contain borax. A sampling of images using a camera phone brand Xiaomi Note 5 by mixing borax in the original sauce before the sample is used for the training and testing process. Figure 3. shows some sample images of tomato sauce used.

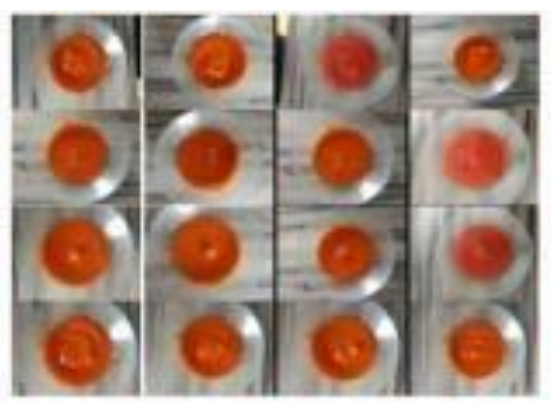

Figure 3 Examples of Several Samples of Tomato Sauce Image Used

Table 1. Test results for the classification of borax content $70 \%$ training and $30 \%$ testing

\begin{tabular}{|c|c|c|c|c|}
\hline & Original & $\begin{array}{c}\text { Borax } \\
30 \%\end{array}$ & $\begin{array}{c}\text { Borax } \\
50 \%\end{array}$ & $\begin{array}{c}\text { Borax } \\
70 \%\end{array}$ \\
\hline Original & 0.89 & 0 & 0.05 & 0.06 \\
\hline $\begin{array}{c}\text { Borax } \\
30 \%\end{array}$ & 0.02 & 0.94 & 0 & 0.04 \\
\hline $\begin{array}{c}\text { Borax } \\
50 \%\end{array}$ & 0 & 0.13 & 0.83 & 0.05 \\
\hline $\begin{array}{c}\text { Borax } \\
70 \%\end{array}$ & 0.05 & 0.09 & 0 & 0.86 \\
\hline
\end{tabular}

In table 1, illustrate the results of the classification of borax content using GLCM with $70 \%$ training and $30 \%$ testing. In the original tomato sauce image GLCM is able to classify with an average accuracy rate of $89 \%$, in the $30 \%$ content content borax GLCM is able to classify with an average accuracy rate of $94 \%$, image content of $50 \%$ borax with an average accuracy rate of $83 \%$ and image $70 \%$ borax content with an average accuracy rate of $86 \%$. The overall results of the classification system of borax content in tomato sauce using GLCM are implemented in Figure 4. 


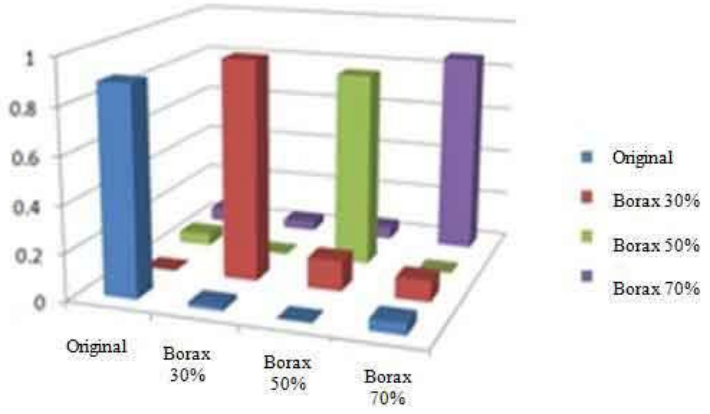

Figure 4. Overall Graph of Borax Content Classification Systemn On Tomato Sauce Using GLCM

\section{Conclusion ANd Suggestion}

The results showed that the gray level cooccurrence matrix (GLCM) method was quite optimal in classifying tomato sauce data containing borax and not with an average percentage of the introduction of $88 \%$, to improve the quality of the gray level co-occurrence matrix (GLCM) performance. can add another approach to the classification process. The addition of this approach will certainly affect the computational speed and accuracy of the classification process.

\section{REFERENCES}

Indriani, O. R., Kusuma, E. J., Sari, C. A., Rachmawanto, E. H., \& Setiadi, D. R. (2017). Tomatoes Classification Using KNN Based on. International Conference on Innovative and Creative Information Technology (ICITech).

Lathifah, Q. A., Turista, D. D., Azizah, L., \& Khulaifi, A. E. (2019). Identification of formalin and borax on tuna in Ngemplak market Tulungagung regency. Medical Laboratory Analysis and Sciences Journal, 1(1).
Nkhata, S. G., \& Ayua, E. O. (2018). Quality attributes of homemade tomato sauce stored at. African Journal of Food Science, 12(5).

Nursari, N., Karimuna, L., \& Tamrin, T. (2016). PENGARUH $\mathrm{pH}$ DAN SUHU PASTEURISASI TERHADAP KARAKTERISTIK KIMIA, ORGANOLEPTIK DAN DAYA SIMPAN SAMBAL. J. Sains dan Teknologi Pangan (JSTP), 1(2), 151-158.

Öztürka, Ş., \& Akdemir, B. (2018). Application of Feature Extraction and Classification Methods for Histopathological Image using GLCM, LBP, LBGLCM, GLRLM and SFTA. Procedia Computer Science.

Ray, S., Saha, R., Raychaudhuri, U., \& Chakraborty, R. (2016). DIFFERENT QUALITY CHARACTERISTICS OF TOMATO (SOLANUM LYCOPERSICUM) AS A FORTIFYING INGREDIENT IN FOOD PRODUCTS: A REVIEW. Technical Sciences, 19(3).

Rizal, R. A., Gulo, S., Sihombing, O. D., Napitupulu, A. B., Gultom, A. Y., \& Siagian, T. J. (2019). ANALISIS GRAY LEVEL COOCCURRENCE MATRIX (GLCM) DALAM MENGENALI CITRA EKSPRESI WAJAH. Jurnal Mantik, 3(2).

Sukiman, T. S., Suwilo, S., \& Zarlis, M. (2019). Feature Extraction Method GLCM and LVQ in Digital Image-Based Face Recognition. SINKRON, 4(1).

Usman, N. B., Herawati, N., \& Fitriani, S. (2019). Quality of Sauce with Basic Ingredients of Tomatoes, Carrots and Red Palm Oil. JURNAL TEKNOLOGI PANGAN, 13(2).

Xie, C., Shao, Y., Li, X., \& He, Y. (2015). Detection of early blight and late. Scientific Reports. 